\title{
Sex-specific differences in antithrombotic therapy and prognosis in patients with acute coronary syndrome treated with stent
}

\author{
Diferencias en el tratamiento antitrombótico y pronóstico en función del sexo en \\ pacientes con síndrome coronario agudo tratados con stent
}

Javier Jimeno-Sánchez*, Georgina Fuertes-Ferre, Alejandra Ruiz-Aranjuelo, Isabel Caballero-Jambrina, José A. Diarte-de Miguel, and María R. Ortas-Nadal

Department of Cardiology, Hospital Universitario Miguel Servet, Zaragoza, Spain

\begin{abstract}
Aims and objective: Impact of sex-related differences in patients with the acute coronary syndrome (ACS) undergoing percutaneous coronary intervention and treated with new P2Y12 inhibitors is not adequately characterized. We aimed to analyze gender-based differences in dual antiplatelet therapy, and adverse cardiovascular events. Materials and methods: Prospective-observational study of the consecutive ACS patients treated with stent from July 2015 to January 2016, with a follow-up of 1 year. Results: We examined 283 patients, 75 (26.5\%) women and 208 (73.5\%) men. Women were older than men (71 \pm 13 vs. $66.5 \pm 13$ years). There were $44 \%$ of women and $52 \%$ of men presenting with ST-elevation ACS $(p=0.21)$. Women had a higher bleeding risk (CRUSADE), without differences in the ischemic risk (Global Registry of Acute Coronary Events and thrombolysis in myocardial infarction). More women were treated with drug-eluting stent ( $88.9 \mathrm{vs.} 75.5 \%, p=0.04)$. There was a lower rate of ticagrelor prescription in women (42.6 vs. $50.9 \%, p=0.29$ ), in favor of clopidogrel. No differences were observed in the prasugrel prescription. No significant differences were observed after a year of follow-up, but women had a tendency toward lower mortality (1.4 vs. 6.7\%, $p=0.19$ ) and higher bleeding rates (23.3 vs. $17.4 \%, p=0.27)$. Conclusions: In our study of patients presenting with ACS treated with stent, clopidogrel was preferred in women, whereas ticagrelor was the most frequent prescription in men. No significant differences were noted in clinical outcomes, but women experienced a tendency toward less mortality and more bleeding events.
\end{abstract}

Key words: Acute coronary syndrome. Dual antiplatelet therapy. Percutaneous coronary intervention. Sex. Bleeding. Mortality.

\section{Resumen}

Antecedentes y objetivo: El interés sobre la influencia del sexo en pacientes con síndrome coronario agudo (SCA) tratados con stent y nuevos antiagregantes inhibidores de P2Y12 en la práctica clínica es creciente. Se analizan las diferencias en

Available online: 06-09-2019 Arch Cardiol Mex (Eng). 2019;89(4):301-309 www.archivoscardiologia.com 2604-7063/C 2019 Instituto Nacional de Cardiología Ignacio Chávez. Published by Permanyer. This is an open access article under the CC BY-NC-ND license (http://creativecommons.org/licenses/by-nc-nd/4.0/). 
función del sexo en el tratamiento con doble antiagregación plaquetaria (DAPT) y los eventos adversos isquémicos y hemorrágicos. Materiales y métodos: Estudio prospectivo de pacientes consecutivos con diagnóstico de SCA tratados con stent coronario desde julio de 2015 hasta enero de 2016. Resultados: De un total de 283 pacientes incluidos, 75 (26.5\%) correspondió a mujeres y 208 (73.5\%) a hombres. La edad media fue de $71 \pm 13$ y $66.5 \pm 13$ años, respectivamente. Un $44 \%$ de mujeres se presentó como SCA con elevación del segmento ST contra un 52.4 de los hombres, $p=0.21$. Las mujeres mostraron un mayor riesgo de sangrado (CRUSADE), sin diferencias en el riesgo isquémico (GRACE y TIMI). Se usaron stents farmacoactivos con más frecuencia en mujeres (88.9 vs. $75.5 \%, p=0.04)$. Se observó una tendencia de menor prescripción del ticagrelor en mujeres (42.6 vs. $50.9 \%, p=0.29)$ en favor de un mayor uso del clopidogrel. No se identificaron diferencias en cuanto a la prescripción del prasugrel. Las mujeres presentaron al año una menor mortalidad (1.4 vs. 6.7\%, $p=0.19$ ), aunque mayor sangrado (23.3 vs. $17.4 \%, p=0.27$ ). Conclusiones: En este estudio de pacientes consecutivos con SCA tratados con stent se registró una mayor prescripción de clopidogrel en las mujeres que en los hombres. Las mujeres presentaron una menor incidencia anual de mortalidad, pero mayor sangrado en comparación con los hombres, no significativo.

Palabras clave: Síndrome coronario agudo. Doble antiagregación. ICP. Sexo. Sangrado. Mortalidad.

\section{Introduction}

Cardiovascular diseases are the main cause of mortality in the world and are expected to cause more than 23.3 million deaths by the year $2030^{1}$. According to the World Health Organization, these alterations caused $32 \%$ of all deaths in women and $27 \%$ in men in $2004^{2}$. Although coronary heart disease-related mortality is higher in men, in the past few decades, there has been a disproportionate increase in mortality in women $^{3,4}$. In Spain, coronary disease is also more common in men, although in acute coronary syndrome (ACS), notable gender differences have been described in terms of pathophysiology, clinical characteristics, prognosis, and treatment ${ }^{5,6}$.

The combination of antithrombotic treatment (including double antiplatelet therapy) and percutaneous coronary intervention $(\mathrm{PCl})$ is the regular treatment for ACS and significantly reduces the risk of mortality and major adverse cardiovascular events (MACE), at the expense of an increased risk of bleeding ${ }^{7,8}$. In this sense, the new and stronger P2Y12 inhibitors ticagrelor and prasugrel have demonstrated higher efficacy than clopidogrel in the prevention of ischemic events ${ }^{9,10}$, which is similar in both genders ${ }^{11,12}$. However, an increased risk of bleeding complications has been described with ticagrelor and prasugrel in comparison with clopidogre $\left.\right|^{9,10}$. On the other hand, belonging to the female gender is an independent risk factor for bleeding in patients with $\mathrm{ACS}^{3,12-14}$.

Evidence in clinical practice about gender-related differences in the antithrombotic treatment given to patients with ACS treated with stent is scarce. The purpose of this study is to analyze gender-secondary differences in the treatment with dual antiplatelet therapy (DAPT) and their prognostic implications with regard to MACE and bleeding.

\section{Patients and methods}

\section{Study design}

This study follows a prospective analytical observational design with consecutive patients admitted at the Miguel Servet University Hospital of Zaragoza (Spain), who were diagnosed with ACS and treated with coronary stent from July 2015 to January 2016 . All the information collected in this work is part of daily clinical practice and has the authorization of the Research Ethics Committee of the Autonomous Community of Aragón. For each patient, demographic and anthropometric data, clinical history, and analytical parameters were collected at admission, in addition to information on the $\mathrm{PCl}$, procedure performed. Therapeutic antithrombotic care on admission and at discharge was decided by the doctor responsible for each patient according to his/her clinical judgment and current guidelines. The follow-up was carried out through the event log available in the Electronic Medical Record of the Aragonese Health System and through telephone interviews.

\section{Objectives}

The main objective of the study was to analyze gender-related differences in the treatment with DAPT. The secondary objective was to describe divergences in relation to MACE and bleeding in terms of gender. MACE was defined as the combined episode of cardiovascular death, non-lethal AMI, need for revascularization of the causal lesion, and definitive stent thrombosis. 
Table 1. Patient characteristics

\begin{tabular}{|c|c|c|c|}
\hline & Women $(n=75)$ & Men ( $n=208)$ & $\mathbf{p}$ \\
\hline Age (mean \pm SD) & $70.9 \pm 13.4$ & $66.5 \pm 13.2$ & 0.01 \\
\hline Body mass index (mean \pm SD) & $27.76 \pm 5.3$ & $27.58 \pm 3.6$ & 0.77 \\
\hline Hypertension (n, \%) & $55(75 \%)$ & $125(61 \%)$ & 0.03 \\
\hline Dyslipidemia (n, \%) & $39(53 \%)$ & $99(48 \%)$ & 0.47 \\
\hline Diabetes (n, \%) & $22(31 \%)$ & $64(32 \%)$ & 0.85 \\
\hline Smoking (n, \%) & $17(26 \%)$ & $74(46 \%)$ & $<0.01$ \\
\hline Chronic kidney disease (n, \%) & $13(18.8 \%)$ & $31(15.4 \%)$ & 0.51 \\
\hline Atrial fibrillation (n, \%) & $7(10 \%)$ & $20(9.8 \%)$ & 0.96 \\
\hline Previous ischemic heart disease $(n, \%)$ & $19(27.1 \%)$ & $50(24.8 \%)$ & 0.69 \\
\hline Peripheral vascular disease $(\mathrm{n}, \%)$ & $7(10.1 \%)$ & $25(12.5 \%)$ & 0.67 \\
\hline Ejection fraction $<35 \%(n, \%)$ & $5(8.1 \%)$ & $11(6.1 \%)$ & 0.58 \\
\hline Previous stroke (n, \%) & $7(9.9 \%)$ & $17(8.5 \%)$ & 0.72 \\
\hline STE-ACS (STEMI) (n, \%) & $33(44 \%)$ & $109(52.4 \%)$ & 0.21 \\
\hline NSTE-ACS (NSTEMI/unstable angina) (n, \%) & $42(56 \%)$ & $99(47.6 \%)$ & \\
\hline CRUSADE risk (mean \pm SD) & $37.92 \pm 13$ & $29.14 \pm 17$ & 0.01 \\
\hline TIMI risk* $($ mean \pm SD) & $3.34 \pm 1.2$ & $3.6 \pm 1.4$ & 0.09 \\
\hline GRACE risk* $($ mean \pm SD) & $123 \pm 26$ & $117 \pm 32$ & 0.56 \\
\hline
\end{tabular}

Values are presented as means \pm SD or percentages.

*In patients with STE-ACS.

STE-ACS: ST-segment-elevation acute coronary syndrome; NSTE-ACS: non-ST-segment-elevation acute coronary syndrome; SD: standard deviation.

Major bleeding, as indicated by the thrombolysis in myocardial infarction (TIMI) criteria $^{13}$, included intracranial hemorrhage or a hemoglobin $>5 \mathrm{~g} / \mathrm{dL}$ or hematocrit $\geq 15 \%$ drop. Minor bleeding was defined as any kind of clinically relevant hemorrhage requiring assistance and not meeting the above-described criteria. Patients with a Global Registry of Acute Coronary Events (GRACE) scale score $>140$ were considered as having high-risk ACS, while those with a CRUSADE scale score $>40$ were regarded as being at high hemorrhagic risk.

\section{Statistical analysis}

Qualitative variables were presented as percentages and were compared with Pearson's Chi-square test. Continuous variables were presented as the mean and standard deviation and were compared with Student's t-test or non-parametric tests, as appropriate. MACE and bleeding accumulated incidence were calculated with the Kaplan-Meier method, and the groups were compared with the log-rank test. The influence of gender on MACE and hemorrhagic events was evaluated through logistic regression univariate analysis.

$p<0.05$ was considered statistically significant for all analyses. Statistical analysis was carried out using the SPSS program, version 20.0, for Windows (SPSS, Inc., Chicago, Illinois, USA).

\section{Results}

A total of 283 ACS-diagnosed patients were treated with $\mathrm{PCl}$ and stent implantation; 75 were women $(26.5 \%)$ and 208 were men (73.5\%). The mean age was $70.9 \pm 13.4$ and $66.5 \pm 13.2$ years, respectively. Women had a higher prevalence of hypertension (75.3 vs. $65.3 \%, p=0.03$ ) and lower prevalence of smoking ( 26.2 vs. $45.7 \%, p=0.007$ ), with no significant differences being observed in body mass index or prevalence of dyslipidemia, diabetes, chronic kidney disease, atrial fibrillation, and previous stroke.

ST-segment-elevation ACS was the clinical presentation in $44 \%$ of women versus $52.4 \%$ of men ( $p=0.21)$. Women showed a higher bleeding risk on the 
Table 2. Intervention and treatment characteristics

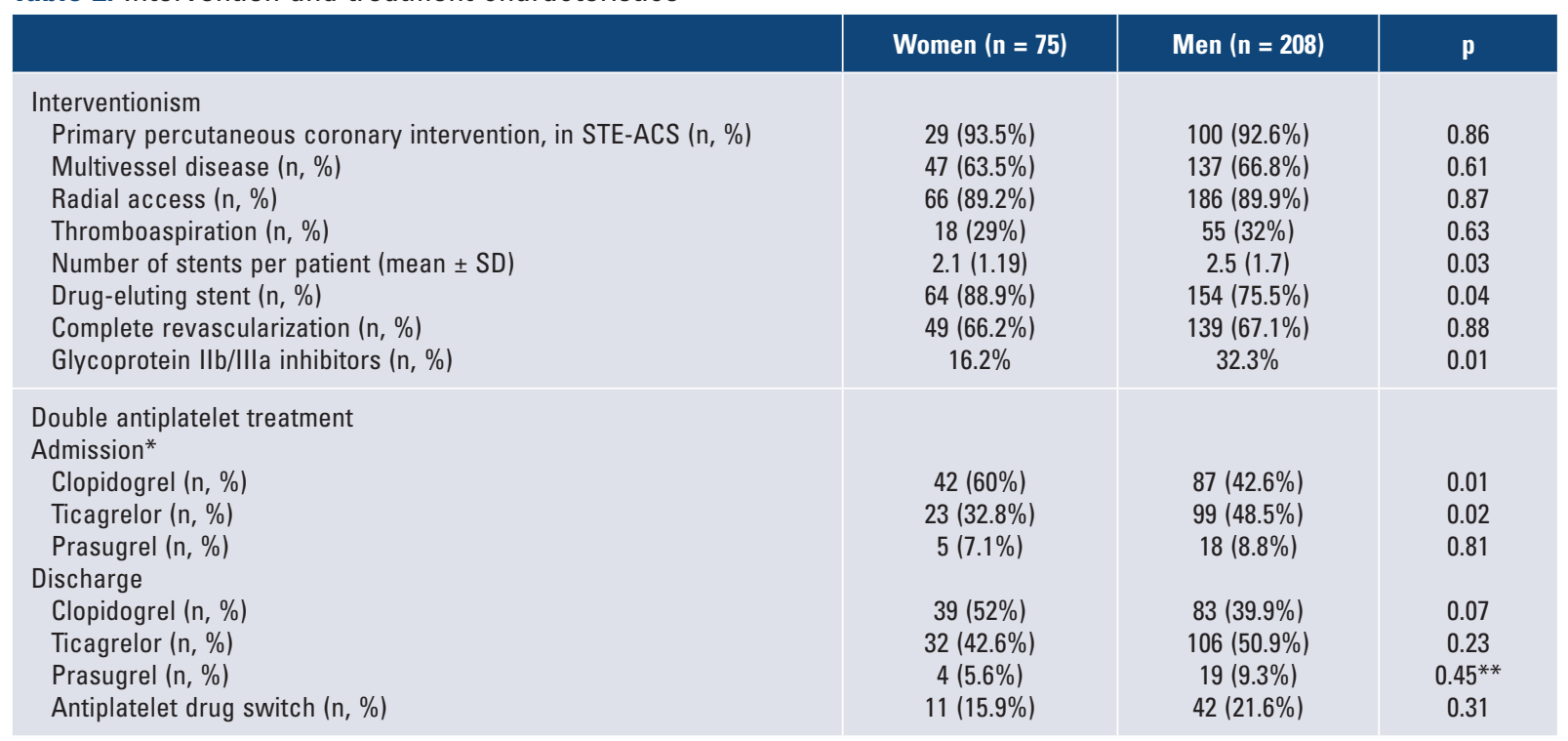

*Among 274 patients $(96.81 \%)$ with P2Y12 receptor inhibitor at admission, 70 women and 208 men; SD: standard deviation.

** Fisher's exact test. Values are presented as means \pm SD or percentages.

CRUSADE scale (37.92 vs. 29.14, $p=0.01$ ), with no significant differences in ischemic risk as measured by the GRACE and TIMI scales in patients who presented with non-ST-segment-elevation ACS (Table 1).

No differences were observed with regard to primary $\mathrm{PCl}$ in patients with ST-segment-elevation ACS $(93.5 \%$ in women vs. $92.6 \%$ in men). Radial access was the most commonly used in both genders (89.2 and $89.9 \%)$. The prevalence of multivessel disease was high in both genders (63.5 and 68.8\%, $p=0.61$ ). Glycoprotein $\mathrm{llb} /$ IIla inhibitors were used to a larger extent in men (16.2 vs. $32.3 \%, p=0.01$ ), as drug-eluting stents were in women (88.9 vs. $75.5 \%, p=0.04$ ).

Regarding the DAPT selection, lower prescription of ticagrelor at admission was identified in women (32.8 vs. $48.5 \%, p=0.02$ ); clopidogrel was the preferred agent as P2Y12 receptor-inhibitor antiplatelet drug in the female gender ( 60 vs. $42.6 \%, p=0.01$ ). In contrast, ticagrelor was the preferred initial drug in men. At discharge, clopidogrel was prescribed in 52\% of women and in $39.9 \%$ of men ( $p=0.07$ ), as well as ticagrelor in $42.6 \%$ of women and $50.9 \%$ of men $(p=0.23)$. There were no significant differences in terms of prasugrel prescription which was the less commonly used drug. An antiplatelet agent switch was observed in 15.9 and $21.6 \%$ of women and men, respectively $(p=0.31)$ (Table 2). Specifically, the switch from clopidogrel to ticagrelor represented $58.5 \%$, and from ticagrelor to clopidogrel, $41.5 \%$, without differences in terms of gender. DAPT was prematurely discontinued by $10 \%$ of women and $19.6 \%$ of males ( $p=0.07$ ). Revascularization was complete in $66.2 \%$ of women and in $67.1 \%$ of men, with no significant differences being observed.

There were no significant differences in the combined event of cardiovascular death, non-lethal AMI, need for revascularization of the causal lesion, and definitive stent thrombosis after 1 year of follow-up (5.3\% in women and $10.6 \%$ in men, $p=0.39)$. Women had lower total and non-significant cardiovascular mortality (Fig. 1), with similar rates of myocardial infarction (5.3\% in women and $6.7 \%$ in men, $p=0.84$ ) and stent thrombosis $(2.5 \%$ in women and $2 \%$ in men, $p=0.84)$. In addition, a greater non-significant trend toward cerebrovascular and hemorrhagic events was observed in women. Specifically, after 1 year of follow-up, women showed a $23.3 \%$ rate of all-cause bleeding versus $17.4 \%$ in men $(p=0.27)$; the incidence of bleeding was higher: 8 and $5.2 \%$, respectively $(p=0.40)$. The Kaplan-Meier curve for all-cause bleeding (Fig. 2) shows a higher, non-significant incidence in the female gender (log-rank test $=0.27$ ). When the different types of bleeding were analyzed according to their source, there were no statistically significant gender-related differences (Table 3).

\section{Discussion}

The main findings of this study of consecutive patients with ACS treated with a stent are as follows: 


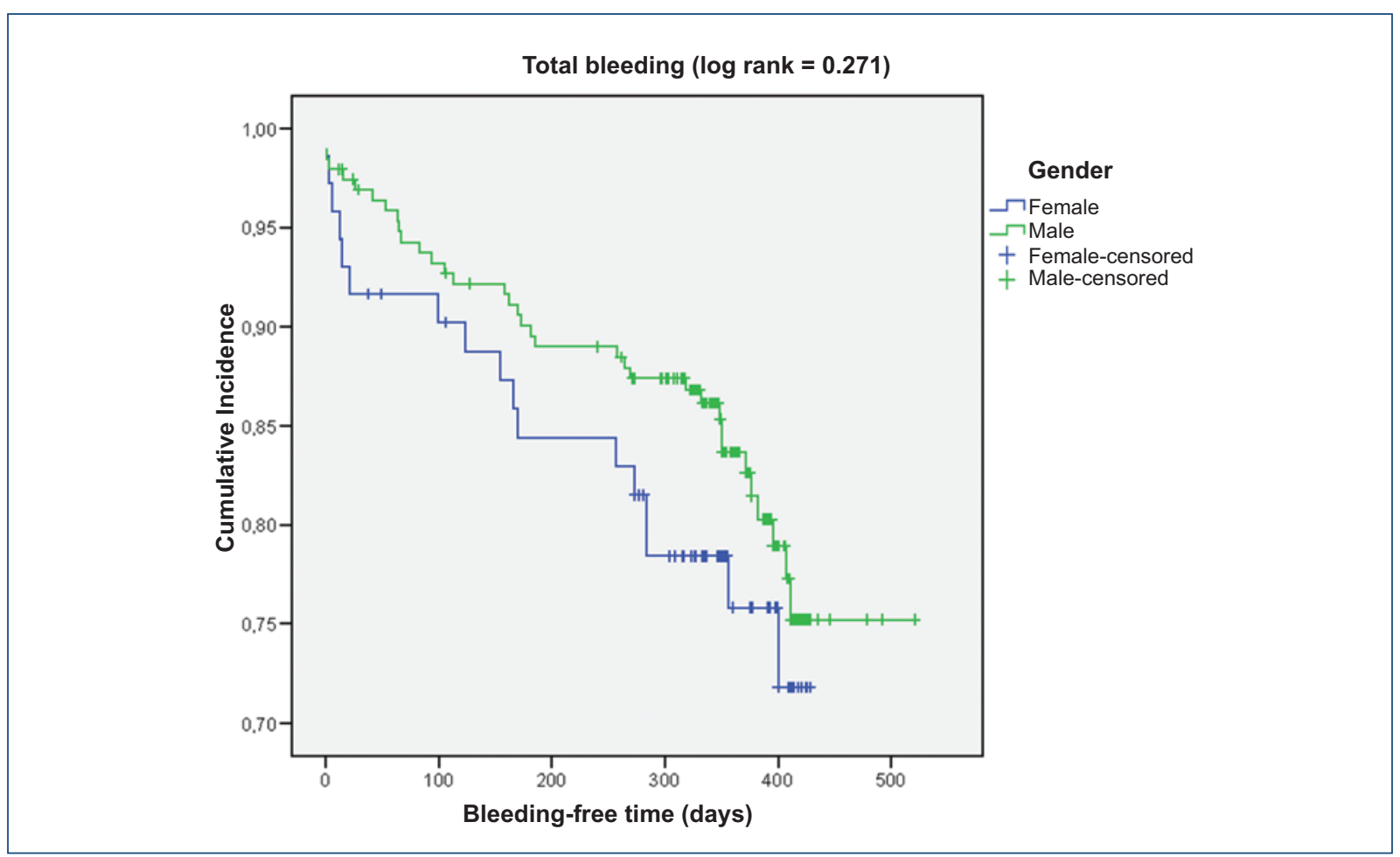

Figure 1. Cumulative incidence of hemorrhagic events in males and females after a 1-year follow-up.

1. There are gender-associated differences with regard to prescription of the strongest platelet $\mathrm{P} 2 \mathrm{Y} 12$ receptor inhibitor anti-aggregation drugs, with higher use of clopidogrel in women and ticagrelor in men

2. Women showed a higher incidence of hemorrhagic events and lower mortality in the 1-year follow-up in comparison with men, without the difference reaching statistical significance.

Multiple previous studies have shown gender-related differences in patients with ACS. For example, women are typically 6-10 years older and have a higher risk profile with more prevalence of hypertension, dyslipidemia, and diabetes, although with a lower rate of smoking $^{5,14}$. In this study, women were older and had higher blood pressure figures, with no differences in the other comorbidities. On the other hand, chest pain is the most common symptom in both genders, although women can exhibit a more atypical ACS clinical presentation $^{3}$ and seek medical assistance with greater delay ${ }^{16}$. Women accounted for a small percentage in this cohort: only one woman with ACS treated with stent was included for every four men. In Spain, according to the RECALCAR registry data, in the year 2013, there was a lower rate of admission for ACS in women for all ages, which represents a higher rate of hospital mortality and hemorrhagic complications ${ }^{17}$. Regarding ACS-related mortality, different studies have described a higher risk in women within comparison with men $^{17-19}$. Previously-described baseline differences such as older age and comorbidities, along with a delay in the time for seeking health assistance, might explain this higher ischemic risk reflected in an increase in mortality. In addition, women have been described as having etiopathogenic non-atherosclerotic ACS mechanisms more often, such as microvascular angina, endothelial dysfunction, and spontaneous coronary dissection ${ }^{15}$. Consistently with data from this study, women with ACS usually suffer non-ST-segment-elevation acute myocardial infarction or unstable angina more frequently in comparison with men, whereas clinical presentation in the form of ST-segment-elevation acute myocardial infarction is less common ${ }^{15}$. Furthermore, in recent years, it has been pointed out that women receive interventional treatment with less frequency ${ }^{5,6,17}$. In this study, although only patients with ACS treated with stent were included, the high rate of primary $\mathrm{PCl}$ in both genders alike stands out $(93.5 \%$ women vs. $92.6 \%$ men). Radial access was also identified as the most commonly used, without differences between both genders, in accordance with current recommendations. Finally, in this cohort, drug-eluting stents were used to a larger extent in women (88.9 vs. $75.5 \%$ ), perhaps due to the smaller diameter of their coronary arteries in comparison with males. 


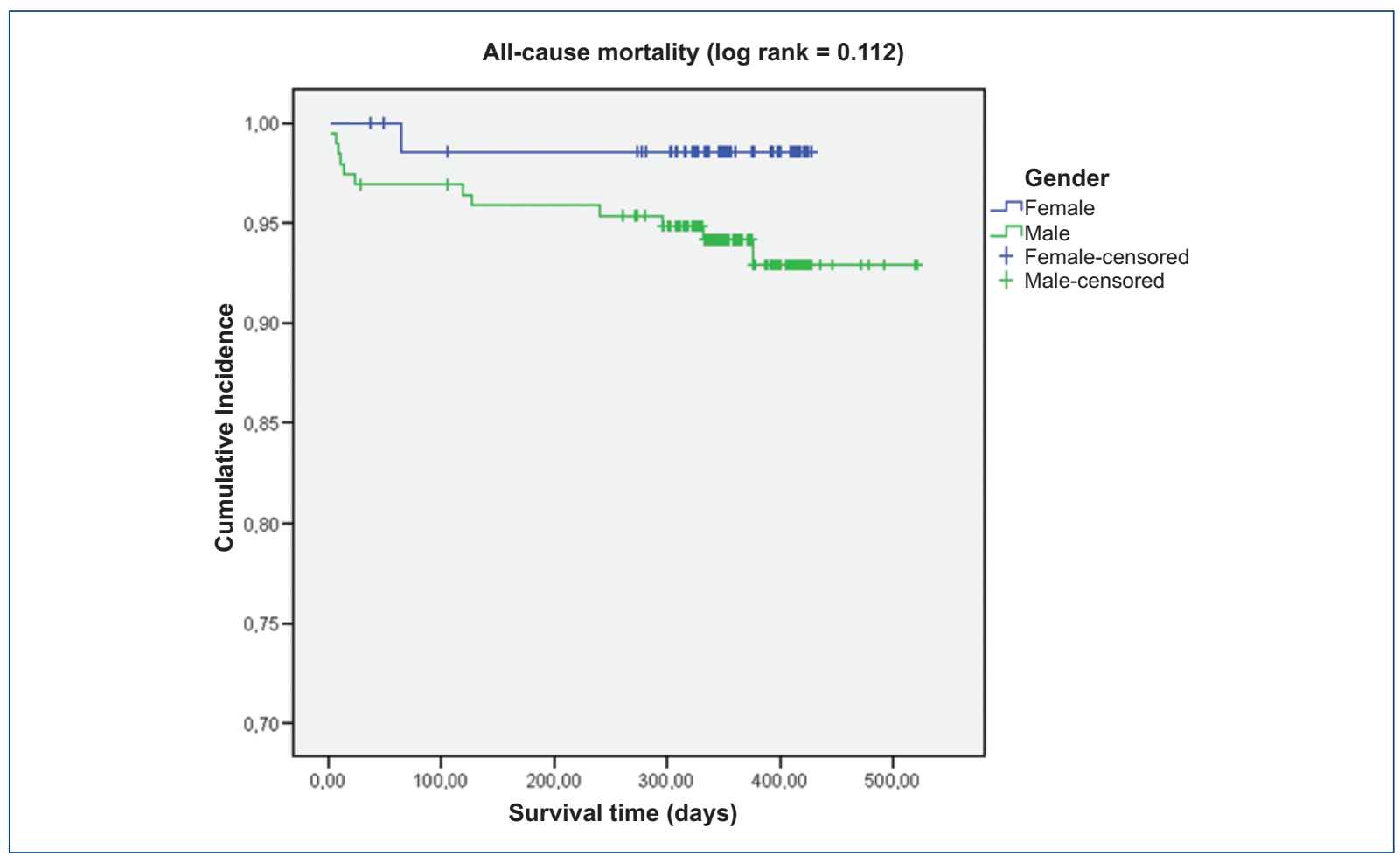

Figure 2. Cumulative incidence of all-cause mortality in males and females after a 1-year follow-up.

On the other hand, no gender-related differences have been demonstrated in the response to ACS pharmacological treatment. According to clinical practice guidelines ${ }^{7,8}$, antiplatelet therapy in patients with ACS treated with stent consists of the combination of acetylsalicylic acid and a second P2Y12-inhibitor antiplatelet drug, ticagrelor $(90 \mathrm{mg} / 12 \mathrm{~h})$ or prasugrel (10 mg/24 h). Clopidogrel ( $75 \mathrm{mg} / 24 \mathrm{~h}$ ) is recommended in case of contraindication for ticagrelor or prasugrel, including patients with a history of intracranial bleeding or when patient hemorrhagic risk is high (anticoagulation indication, etc.).

In this sense, the most recent studies regarding DAPT have shown similar efficacy in women and men, although women especially show a higher hemorrhagic risk $^{12}$. As for clopidogrel, one meta-analysis has shown that it significantly reduces myocardial infarction risk equally in both genders in comparison with acetylsalicylic acid monotherapy, at the expense of increasing hemorrhagic risk (in both genders) ${ }^{20}$. The PLATO ${ }^{10}$ trial revealed a mortality reduction in patients with ACS treated with ticagrelor in comparison with those treated with clopidogrel, without significant differences between women and men. The TRITON-TIMI 38 trial $^{9}$ of prasugrel was the only one to prove a larger absolute (2.4 vs. $1.6 \%$ ) and relative reduction (21 vs. $12 \%$ ) in the risk for MACE in men versus women in comparison with clopidogrel. In any case, current guidelines specify that there is insufficient evidence to differentiate the different treatment types and guidelines based on gender and that ticagrelor and prasugrel, together with acetylsalicylic acid, are the first-choice DAPT both for men and in women ${ }^{7,8,21}$. However, not only less frequent invasive treatment has been described in women but also drug undertreatment ${ }^{22}$. In this study, clopidogrel was statistically significant the initial preferred antiplatelet drug in women along with acetylsalicylic acid, while the first-choice drug for males at admission was ticagrelor. At discharge, although the differences were less evident and ticagrelor was the drug of choice in both genders, higher use of clopidogrel persisted in women. Evidence in this regard is growing, with another recent study that obtained similar results: clopidogrel is prescribed to a larger extent in women than in men $^{23}$. In addition, in this cohort, there was a higher use of glycoprotein Ilb/llla inhibitors in men (16.2 vs. $32.3 \%$ ), which is also an indicator of the more radical antithrombotic treatment used in males.

Probably, the fundamental explanation for this data is the fact that women possess a higher hemorrhagic risk, as consistently described in medical publications $3,6,15,17,23,24$. In a recent prospective study of 1214 patients undergoing catheterization in a tertiary care Spanish hospitall ${ }^{25}$, no significant gender-related 
Table 3. Events after a 1-year follow-up

\begin{tabular}{|c|c|c|c|c|c|}
\hline & Women ( $n=75$ ) & Men ( $n=208)$ & p & OR for men $(95 \% \mathrm{CI})$ & $\mathbf{p}$ \\
\hline Major cardiac adverse events ( $n, \%)$ & $4(5.3 \%)$ & $22(10.6 \%)$ & 0.39 & $1.36(0.66-3.01)$ & 0.37 \\
\hline Cardiovascular mortality (n, \%) & $0(0 \%)$ & $9(4.3 \%)$ & $0.18^{*}$ & & \\
\hline Acute myocardial infarction (n, \%) & $4(5.3 \%)$ & $14(6.7 \%)$ & 0.84 & $1.41(0.45-4.37)$ & 0.56 \\
\hline Definitive stent thrombosis ( $\mathrm{n}, \%$ ) & $2(2.5 \%)$ & $3(2 \%)$ & 0.55 & $0.89(0.31-7.15)$ & 0.66 \\
\hline Stroke $(n, \%)$ & $2(2.6 \%)$ & $3(1.4 \%)$ & 0.54 & $0.54(0.09-3.31)$ & 0.51 \\
\hline All-cause mortality (n, \%) & $1(1.4 \%)$ & $14(6.7 \%)$ & 0.19 & $5.39(0.70-41.74)$ & 0.11 \\
\hline All-cause bleeding (n, \%) & $17(23.3 \%)$ & $35(17.4 \%)$ & 0.27 & $0.69(0.36-1.33)$ & 0.27 \\
\hline Major bleeding (n, \%) & $6(8 \%)$ & $11(5.2 \%)$ & 0.40 & $0.65(0.23-1.18)$ & 0.41 \\
\hline Types of bleeding, percentage of total & & & 0.86 & & \\
\hline Intracranial (n, \%) & $0(0 \%)$ & $2(5.7 \%)$ & & & \\
\hline Urological (n, \%) & $3(17 \%)$ & $6(17.2 \%)$ & & & \\
\hline Digestive (n, \%) & $7(41 \%)$ & $11(31.4 \%)$ & & & \\
\hline Vascular access (n, \%) & $2(12 \%)$ & $4(11.4 \%)$ & & & \\
\hline Epistaxis/cutaneous (n, \%) & $4(25 \%)$ & $9(25.7 \%)$ & & & \\
\hline Others $(\mathrm{n}, \%)$ & $1(5 \%)$ & $3(8.5 \%)$ & & & \\
\hline
\end{tabular}

*Fisher's exact test. Values presented as means \pm SD or percentages. OR: odds ratio; $\mathrm{Cl}$ : confidence interval; SD: standard deviation.

differences were found in the treatment and prognosis of these patients. However, it should be noted that a smaller percentage of women were treated with the new stronger antiplatelet agents, a difference that, according to the study authors, could be explained by the presence of higher hemorrhagic risk. In the authors', women showed a higher risk of bleeding according to the CRUSADE scale, with no significant differences in terms of ischemic risk as measured with the GRACE and TIMI scales. The CRUSADE registry analysis has already revealed a higher rate of major in-hospital bleeding in women, particularly related to the vascular access $^{16}$. Recently, several observational prospective works in patients with ACS treated with stent have indicated a higher hemorrhagic risk in women, without a higher rate of ischemic episodes being demonstrat$\mathrm{ed}^{23,24}$. In turn, another recently published descriptive study based on a large cohort of US contemporary patients undergoing $\mathrm{PCl}$ identified a higher incidence of in-hospital mortality and major bleeding ${ }^{26}$. However, the large clinical trials (TRITON-TIMI $38^{9}$, PLATO $^{10}$, and CHAMPION PHOENIX ${ }^{20}$ ) have not demonstrated the existence of a significant relationship between the antiplatelet treatment and the female gender in terms of hemorrhagic risk. Similarly, according to recent results of the DAPT trial ${ }^{27}$, women and men have a similar late (beyond the $1^{\text {st }}$ year) ischemic and hemorrhagic risk after PCl with stent. These discrepancies between clinical trials' subgroup analyses and real-life observational studies might be due to the reduced representation of women in clinical trials, in addition to a possible dosage excess of antiplatelet agents in real practice by not adjusting to women's weight and kidney function ${ }^{12,15}$. In any case, in this cohort, no significant gender-related differences were identified for prognosis after a 1-year follow-up. A trend toward a higher total incidence of MACE was observed in men, essentially at the expense of an increase in cardiovascular and all-cause mortality. Furthermore, a non-significant higher trend toward hemorrhagic events was identified in women (major and minor bleeding). The Kaplan-Meier curve for total bleeding shows a non-significant higher incidence in the female gender. There were no significant differences either in terms of gender after analyzing the different types of bleeding according to their origin.

This work has certain limitations. First, it is about an observational and single center study, and extrapolation of the results is therefore difficult, and it may be subject to different types of bias. Second, the sample size may have entailed a limitation to obtaining results 
with statistical significance due to the lack of sufficient power to detect differences in adverse events, especially in stent thrombosis.

\section{Conclusions}

In this study of consecutive patients diagnosed with ACS and treated with stent, women represent a small percentage. There are also gender-related differences with regard to the prescription of the strongest P2Y12-inhibitor antiplatelet agents, with higher prescription of clopidogrel being observed in women and of ticagrelor in men. There were no gender-related prognostic differences after a 1-year follow-up, although women had a lower mortality incidence and a non-significant higher all-cause bleeding incidence.

\section{Funding}

No funding of any kind has been received for the conduction of the present work.

\section{Conflicts of interest}

The authors declare that they have no conflicts of interest.

\section{Ethical disclosures}

Protection of people and animals. The authors declare that no experiments were performed on humans or animals for this study.

Confidentiality of data. The authors declare that they have followed the protocols of their work center on the publication of patient data.

Right to privacy and informed consent. The authors declare that no patient data appear in this article.

\section{References}

1. Smith SC Jr, Collins A, Ferrari R, Holmes DR, Logstrup S, McGhie DV, et al. World Heart Federation, American Heart Association; American College of Cardiology Foundation, European Heart Network; European Society of Cardiology. Our time: a call to save preventable death from cardiovascular disease (heart disease and stroke). J Am Coll Cardiol. 2012; 60:2343-2348.

2. World Health Organization. The global burden of disease: 2004 update. www.who.int/healthinfo/global_burden_disease/2004_report_update/en/ index.html (3 August 2015). 2008.

3. Andreotti F, Marchese N. Women and coronary disease. Heart. 2008; 94 (1):108-116.

4. Wenger NK. Prevention of cardiovascular disease in women: highlights for the clinician of the 2011 American Heart Association Guidelines. Adv Chronic Kidney Dis. 2013; 0:419-422.

5. Anguita M, Alonso J, Bertomeu V, Gómez-Doblas J, López-Palop R, Pedreira M. Proyecto de estudio sobre la situación de la enfermedad cardiovascular de la mujer en España: conclusiones y recomendaciones finales. Rev Esp Cardiol. 2008; vol.8, fascículo D.

6. Sanmartín M, Del Val D. Ischemic heart disease in women: a pending issue? Rev Clin Esp. 2016;216(1):19-21.

7. Ibanez B, James S, Agewall S, Antunes MJ, Bucciarelli C, Bueno H, et al. 2017 ESC Guidelines for the management of acute myocardial infarction in patients presenting with ST-segment elevation: The Task Force for the management of acute myocardial infarction in patients presenting with ST-segment elevation of the European Society of Cardiology (ESC). Eur Heart J. 2017.

8. Roffi M, Patrono C, Collet JP, Mueller C, Valgimigli M, Andreotti F, et al. 2015 ESC Guidelines for the management of acute coronary syndromes in patients presenting without persistent ST-segment elevation: Task Force for the Management of Acute Coronary Syndromes in Patients Presenting without Persistent ST-Segment Elevation of the European Society of Cardiology (ESC). Eur Heart J. 2016;37(3):267-315.

9. Wiviott SD, Braunwald E, McCabe CH, Gilles M, Ruzyllo W, Gottlieb S, et al; for the TRITON-TIMI 38 investigators. Prasugrel versus clopidogrel in patients with acute coronary syndromes. $\mathrm{N}$ Engl $\mathrm{J}$ Med. 2007:2001-15.

10. Wallentin L, Becker RC, Budaj A, Cannon CP, Emanuelsson H, Held C et al; PLATO investigators. Ticagrelor versus clopidogrel in patients with acute coronary syndromes. N Engl J Med. 2009; 361: 1045-57.

11. Lau ES, Braunwald E, Murphy SA, Wiviott SD, Bonaca MP, Husted S, et al. Potent P2Y(12) inhibitors in men versus women: a collaborative metaanalysis of randomized trials. J Am Coll Cardiol. 2017 Mar 28;69(12):1549-1559.

12. Wang WT, James SK, Wang TY. A review of sex-specific benefits and risks of antithrombotic therapy in acute coronary syndrome. Eur Heart J. 2017 Jan 14; 38(3):165-171.

13. Chesebro JH, Knatterud G, Roberts R, Borer J, Cohen LS, DAlen J, et al. Thrombolysis in Myocardial Infarction (TIMI) trial. Phase I: a comparison between intravenous tissue plasminogen activator and intravenous streptokinase. Circulation. 1987;76:142-54.

14. Blomkalns AL, Chen AY, Hochman JS, Peterson ED, Trynosky K, Diercks DB, et al; CRUSADE Investigators. Gender disparities in the diagnosis and treatment of non-ST-segment elevation acute coronary syndromes: large-scale observations from the CRUSADE (Can Rapid Risk Stratification of Unstable Angina Patients Suppress Adverse Outcomes With Early Implementation of the American College of Cardiology/ American Heart Association Guidelines) National Quality Improvement Initiative. J Am Coll Cardiol. 2005;45:832-837.

15. Foussas S. Differences in men and women in acute coronary syndromes. Hellenic J Cardiol. 2016; 57: 296-299.

16. Diercks DB, Owen KP, Kontos MC, Blomkains A, Chen AY, Miller C, et al. Gender differences in time to presentation for myocardial infarction before and after a national women's cardiovascular awareness campaign: a temporal analysis from the Can Rapid Risk Stratification of Unstable Angina Patients Suppress ADverse Outcomes with Early Implementation (CRUSADE) and the National Cardiovascular Data Registry Acute Coronary Treatment and Intervention Outcomes Network-Get with the Guidelines (NCDR ACTION Registry-GWTG). Am Heart J. 2010;160:80-87.e3.

17. Calvo Cebollero I, Elola J, Sánchez Insa E. Diferencia de género en cardiopatía isquémica: mitos y realidades. En: Romero Alvira D, Calvo Cebollero I, Sánchez-Rubio J. El corazón de la mujer. $1^{\circ}$ ed. Zaragoza: Limencop; 2016:39-57.

18. Redfors $\mathrm{B}$, Angerås $\mathrm{O}$, Råmunddal $\mathrm{T}$, Petursson $\mathrm{P}$, Haraldsson $\mathrm{I}$, Dworeck $C$, et al. Trends in genderdifferences in cardiac care and outcome after acute myocardial infarction in Western Sweden: a report from the Swedish Web System for Enhancement of Evidence-Based Care in Heart Disease Evaluated According to Recommended Therapies (SWEDEHEART). J Am Heart Assoc. 2015;4:e001995.

19. Akhter N, Milford-Beland S, Roe MT, Piana RN, Kao J, Shroff A. Gender differences among patients with acute coronary syndromes undergoing percutaneous coronary intervention in the American College of Cardiology-National Cardiovascular Data Registry (ACC-NCDR). Am Heart J. 2009;157:141-148.

20. Berger JS, Bhatt DL, Cannon CP, Chen Z, Jiang L, Jones JB, et al. The relative efficacy and safety of clopidogrel in women and men a sex-specific collaborative meta-analysis. J Am Coll Cardiol. 2009;54:1935-1945.

21. Valgimigli M, Bueno $H$, Byrne RA, Collet JP, Costa F, Jeppsson A, et al; ESC Scientific Document Group. 2017 ESC focused update on dual antiplatelet therapy in coronary artery disease developed in collaboration with EACTS: The Task Force for dual antiplatelet therapy in coronary artery disease of the European Society of Cardiology (ESC) and of the European Association for Cardio-Thoracic Surgery (EACTS). European Heart Journal. 2017;0:1-48.

22. Merz CN. The Yentl syndrome is alive and well. Eur Heart J. 2011; 32:1313-1315

23. Xanthopoulou I, Davlouros P, Deftereos S, Hamilos M, Sitafidis G, Ganakakis I et al. Gender-related differences in antiplatelet treatment pat- 
terns and outcome: Insights from the GReekAntiPlatElet Registry. Cardiovasc Ther. 2017;35(4).

24. Solinas E, Vignali L, Ortolani P, et al. Association of bleeding, mortality and sex in acute coronary syndromes: the missing triangle. J Cardiovasc Med. (Hagerstown). 2015;16(5):347-54.

25. Ruiz-Pizarro V, Ferrera C, Gómez-Polo JC, Palacios-Rubio J, Rico-Garcia A, Fernandez-Ortiz A, et al. Sex differences in treatment and prognosis of acute coronary syndrome with interventional management. Cardiovasc Revasc Med. 2019 Mar;20(3):183-186.
26. Potts J, Sirker A, Martínez SC, Gulati M, Alasnag M, Rashid M, et al. Persistent sex disparities in clinical outcomes with percutaneous coronary intervention: Insights from 6.6 million $\mathrm{PCl}$ procedures in the United States. PLOS ONE. 2018; 13(9):e0203325.

27. Berry N, Kereiakes DJ, Yeh RW, Steg PG, Cutlip DE, Jacobs AK, et al. Benefit and risk of prolonged DAPT after coronary stenting in women. Results from the DAPT study. Circulation: Cardiovascular Interventions. 2018;11:e005308. 